\title{
Low-GWP Refrigerant Evaluation in AC Systems for High Ambient Temperature Applications -Design and Simulation Practice to Identify Charge Reduction Opportunities for Residential AC/HP Units- FY18 $3^{\text {rd }}$ Quarter Milestone Report
}

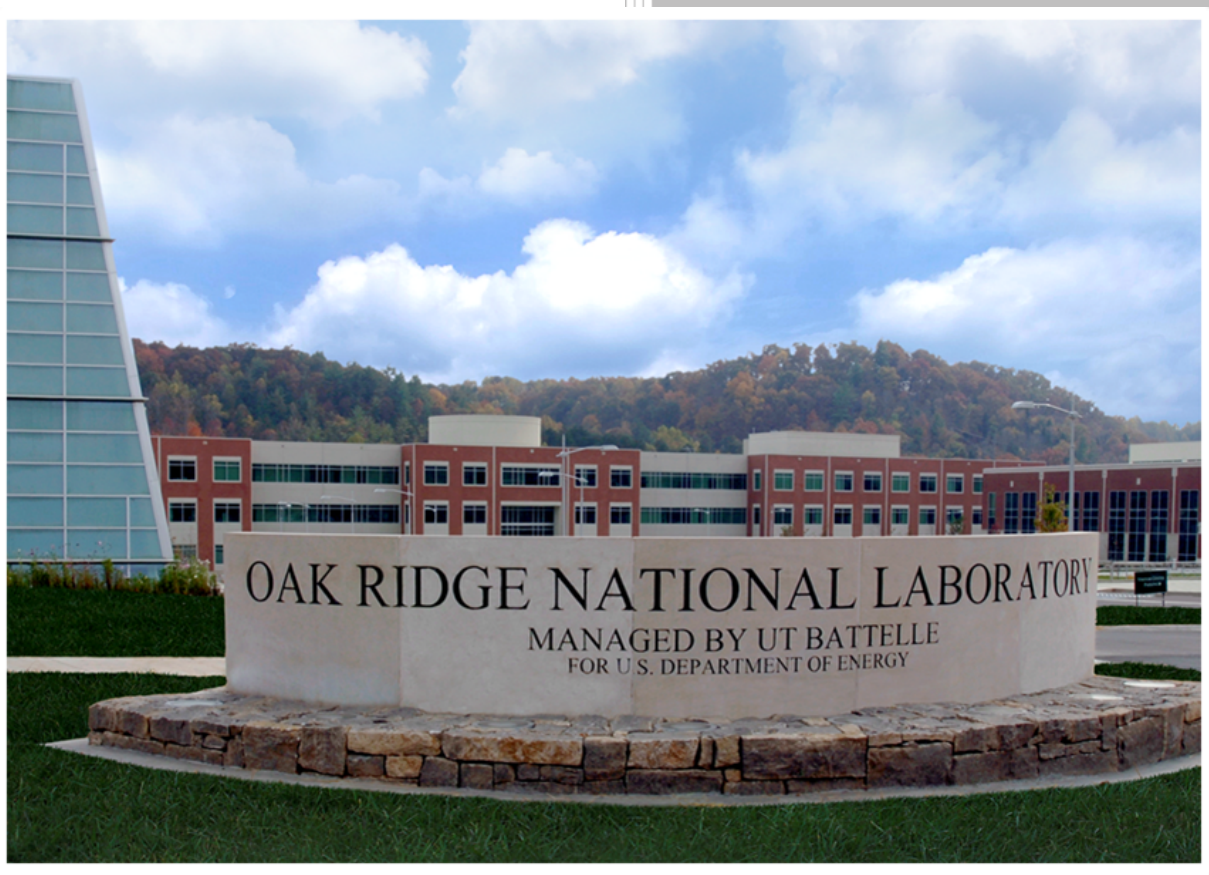

Bo Shen 06/30/2018

Approved for public release. Distribution is unlimited. 


\title{
DOCUMENT AVAILABILITY
}

Reports produced after January 1, 1996, are generally available free via US Department of Energy (DOE) SciTech Connect.

Website http://www.osti.gov/scitech/

Reports produced before January 1, 1996, may be purchased by members of the public from the following source:

\author{
National Technical Information Service \\ 5285 Port Royal Road \\ Springfield, VA 22161 \\ Telephone 703-605-6000 (1-800-553-6847) \\ TDD 703-487-4639 \\ Fax 703-605-6900 \\ E-mail info@ntis.gov \\ Website http://www.ntis.gov/help/ordermethods.aspx
}

Reports are available to DOE employees, DOE contractors, Energy Technology Data Exchange representatives, and International Nuclear Information System representatives from the following source:

Office of Scientific and Technical Information

PO Box 62

Oak Ridge, TN 37831

Telephone 865-576-8401

Fax 865-576-5728

E-mail reports@osti.gov

Website http://www.osti.gov/contact.html

This report was prepared as an account of work sponsored by an agency of the United States Government. Neither the United States Government nor any agency thereof, nor any of their employees, makes any warranty, express or implied, or assumes any legal liability or responsibility for the accuracy, completeness, or usefulness of any information, apparatus, product, or process disclosed, or represents that its use would not infringe privately owned rights. Reference herein to any specific commercial product, process, or service by trade name, trademark, manufacturer, or otherwise, does not necessarily constitute or imply its endorsement, recommendation, or favoring by the United States Government or any agency thereof. The views and opinions of authors expressed herein do not necessarily state or reflect those of the United States Government or any agency thereof. 
BTO Project 3.2.2.19

FY18 $3^{\text {rd }}$ Quarter Milestone Report

Low-GWP Refrigerant Evaluation in AC Systems for High Ambient Temperature Applications - design and simulation practice to identify charge reduction opportunities for residential AC/HP units

\author{
Author \\ Bo Shen
}

Date: 06/30/2018

Prepared by

OAK RIDGE NATIONAL LABORATORY

Oak Ridge, TN 37831-6283

managed by

UT-BATTELLE, LLC

for the

US DEPARTMENT OF ENERGY

under contract DE-AC05-00OR22725 


\section{Design and simulation practice to identify charge reduction opportunities for residential AC/HP units (Regular Milestone)}

\section{Executive Summary}

Based on three 5-ton, single-speed heat pumps (HPs), using R-410A, which use the same compressor, indoor blower and outdoor fan, the DOE/ORNL Heat Pump Design Model was used to conduct comparative modelling study. Regarding charge reduction opportunities, in general, we recommend: 1. Downsizing the outdoor condenser will reduce the required system charge, i.e. using smaller tube diameters or fewer tubes; reducing the evaporator inner volume is less important; to offset the reduced condenser tube side surface area, one can increase the air side surface area (fin density) or condenser air flow rate via using a more efficient fan. 2. microchannel heat exchangers are most effective in reducing the required charge, by up to $60 \%$ in the condenser and evaporator. To develop low charge systems, one should at least use a microchannel heat exchanger as the outdoor condenser. 3. TXV systems are less sensitive to charge reduction. For the drop-in application, one can decrease the charge to minimize the liquid section in the condenser, at the expense of minor performance degradation; for example, when reducing the system charge by $15 \%$ (decrease the subcooling degree to $2 \mathrm{R}$ ), the simulation results prove that the decrease is less than $3 \%$ in the EER and less than $6 \%$ in the capacity.

\section{Smaller condenser size, tube diameters and microchannel heat exchangers lead to charge reduction}

We obtained unit information and heat exchanger geometries for three 5-ton, single-speed heat pumps, using R-410A. The three heat pumps have the same compressor, indoor blower and outdoor fan. They use different heat exchangers. The evaporator and condenser of Unit A (3/8"Coils) use 3/8-inch (9.5 mm outside diameter) tubes; and Unit B (7mmCoils) uses $7 \mathrm{~mm}$ tubes; Unit C (MHXs) uses all microchannel heat exchangers. They have the same rated cooling capacity and similar sensible heat ratio at the AHRI A condition, i.e. $95^{\circ} \mathrm{F}$ outdoor dry bulb temperature, indoor $80^{\circ} \mathrm{F}$ dry bulb $/ 67^{\circ} \mathrm{F}$ wet bulb temperature. The

figure below presents the rated EERs and calculated refrigerant charges (sum of the evaporator and condenser) as a function of the ratio of condenser inner volume to evaporator, of the three units. 


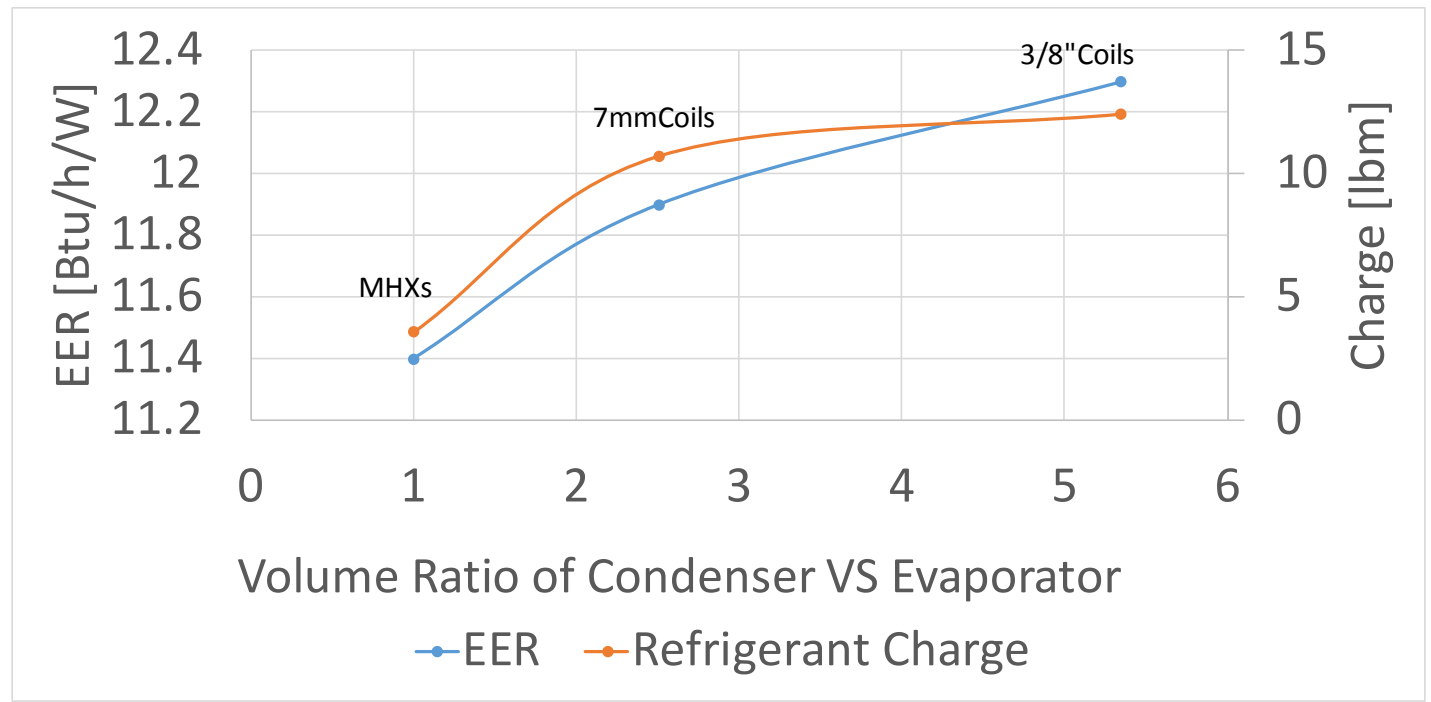

Figure 1: Rated EERs and Refrigerant Charges VS Inner Volume Ratio of Condenser Relative to Evaporator

Figure 1 indicates that the refrigerant charge increases with the tube diameter and relative condenser inner volume. At the same rated capacity, SHR and indoor air flow rate, the indoor evaporator size is relatively fixed. Enlarging the condenser surface area enhances the efficiency while increasing the refrigerant charge. The microchannel heat exchangers can decrease the system charge by $67 \%$ in comparison to the unit using $7 \mathrm{~mm}$ tubes.

Figure 2 illustrates charge mass distribution in evaporator (M_evap) and condenser ( $M$ _cond) when setting the condenser exit subcooling degree at 10R. Additionally, the charge in the condenser splits to four parts, i.e. the charge in the vapor-phase region (M_Vcond), the two-phase region (M_TPcond), the liquid-phase region (M_LIQcond), and in the outlet header (M_Header). In the three units, it can be seen, that more than $70 \%$ of refrigerant charge is in the condenser, primarily in the two-phase and liquid-phase regions. Charge in the liquid header of the microchannel-channel heat exchanger is also noticeable, which takes $20 \%$ of the total charge. For charge reduction, it is most important to control the charge in the condenser, i.e. downsizing the outdoor condenser inner volume. 


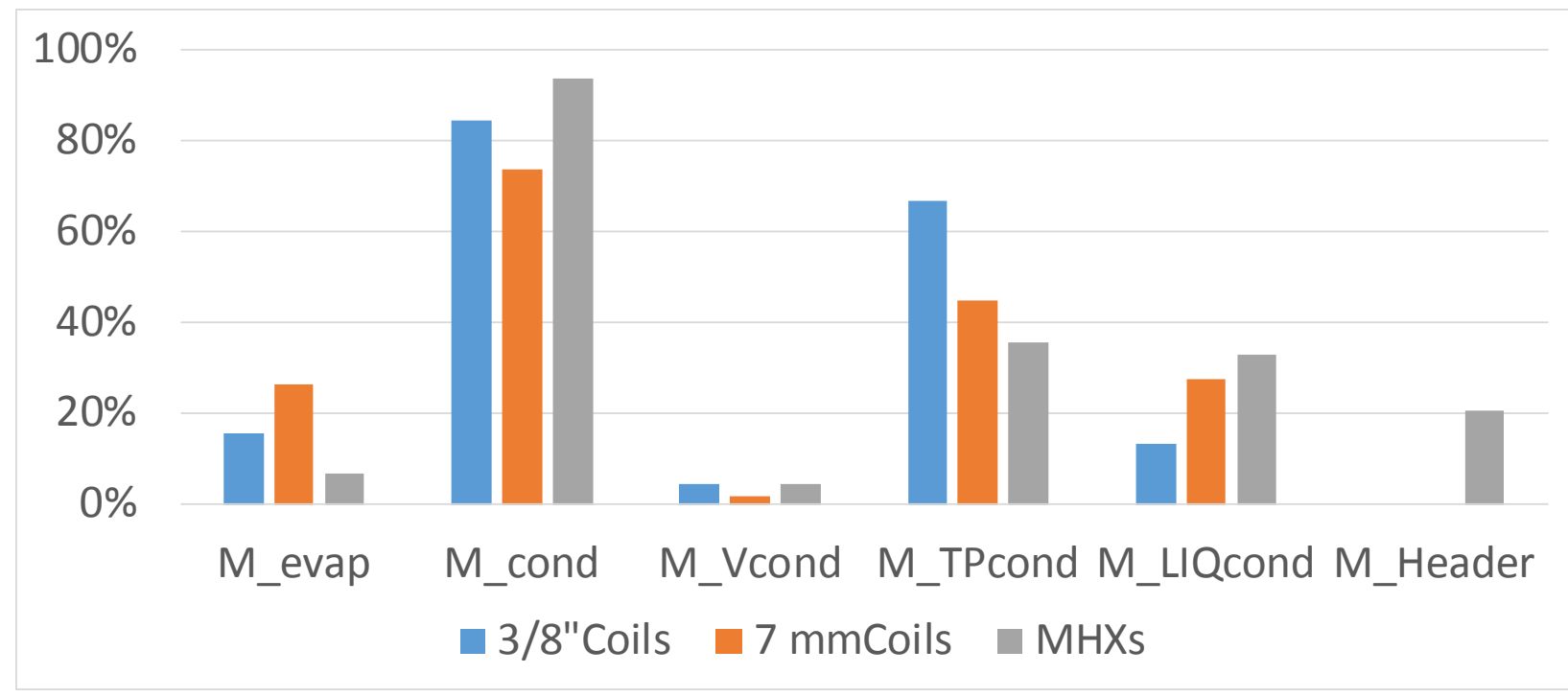

Figure 2: Charge Mass Distribution in Evaporator and Condenser

However, reducing the outdoor condenser inner volume elevates the condensing pressure and degrades the energy efficiency. One can increase the condenser air flow rate or the condenser air side surface area, i.e. fin density, to balance the degradation. On the other hand, these will cause higher air side pressure drop and larger fan power. Hence, it is necessary to use a more efficient condenser fan.

\section{TXV Systems less sensitive to charge variation}

Performance of an Air conditioner using a thermo-expansion valve tends to be insensitive to variation of the system charge. Figures 3 and 4 predict variations of cooling EER and capacity as a function of the system charge relative to the nominal value in the systems using $3 / 8$ inch tubes and microchannel heat exchangers. With reducing the system charge by $15 \%$ (decrease the subcooling degree to $2 \mathrm{R}$ ), the degradation in the EER is less than $3 \%$, and the capacity reduction is less than $6 \%$. 


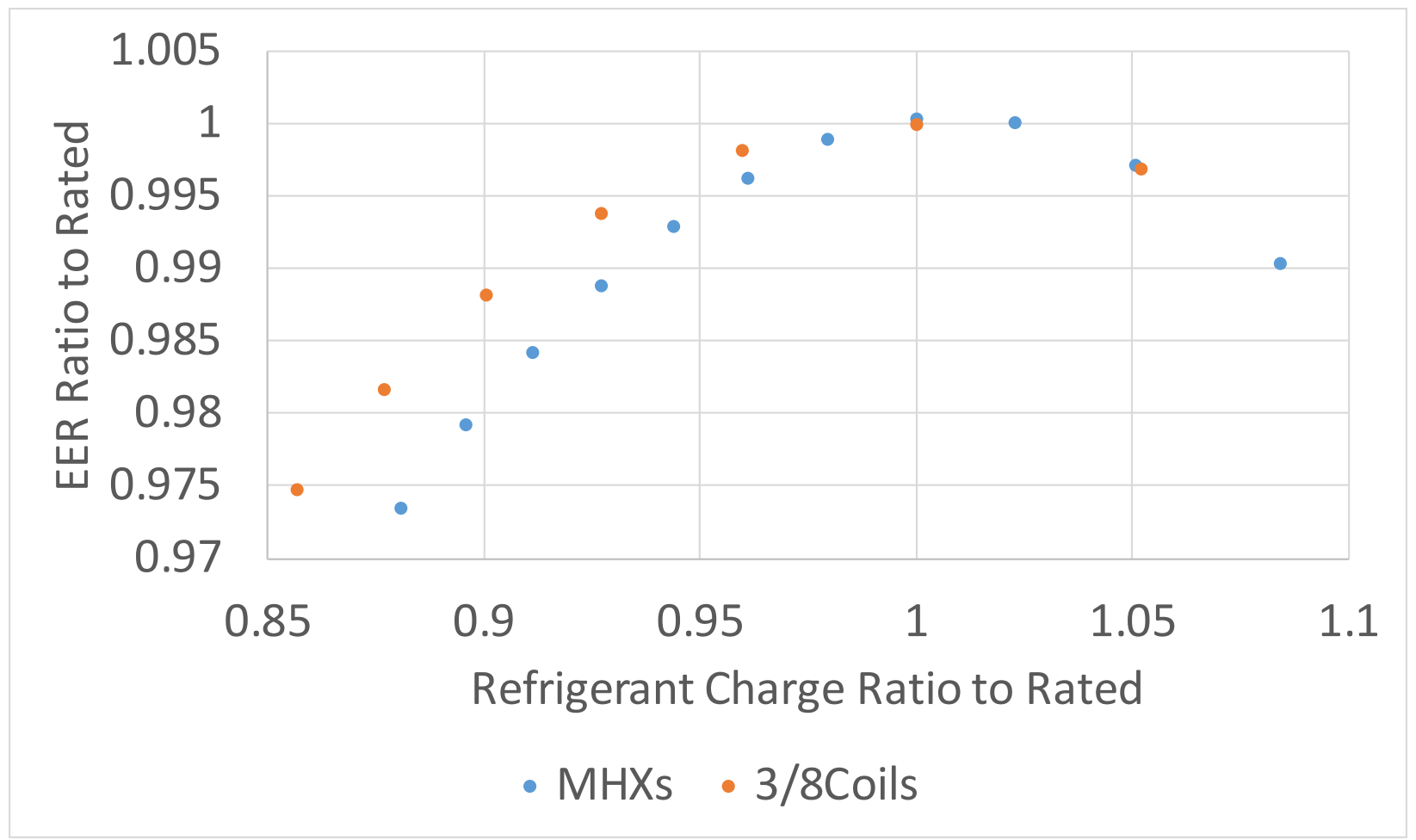

Figure 3: EERs change with the system charge

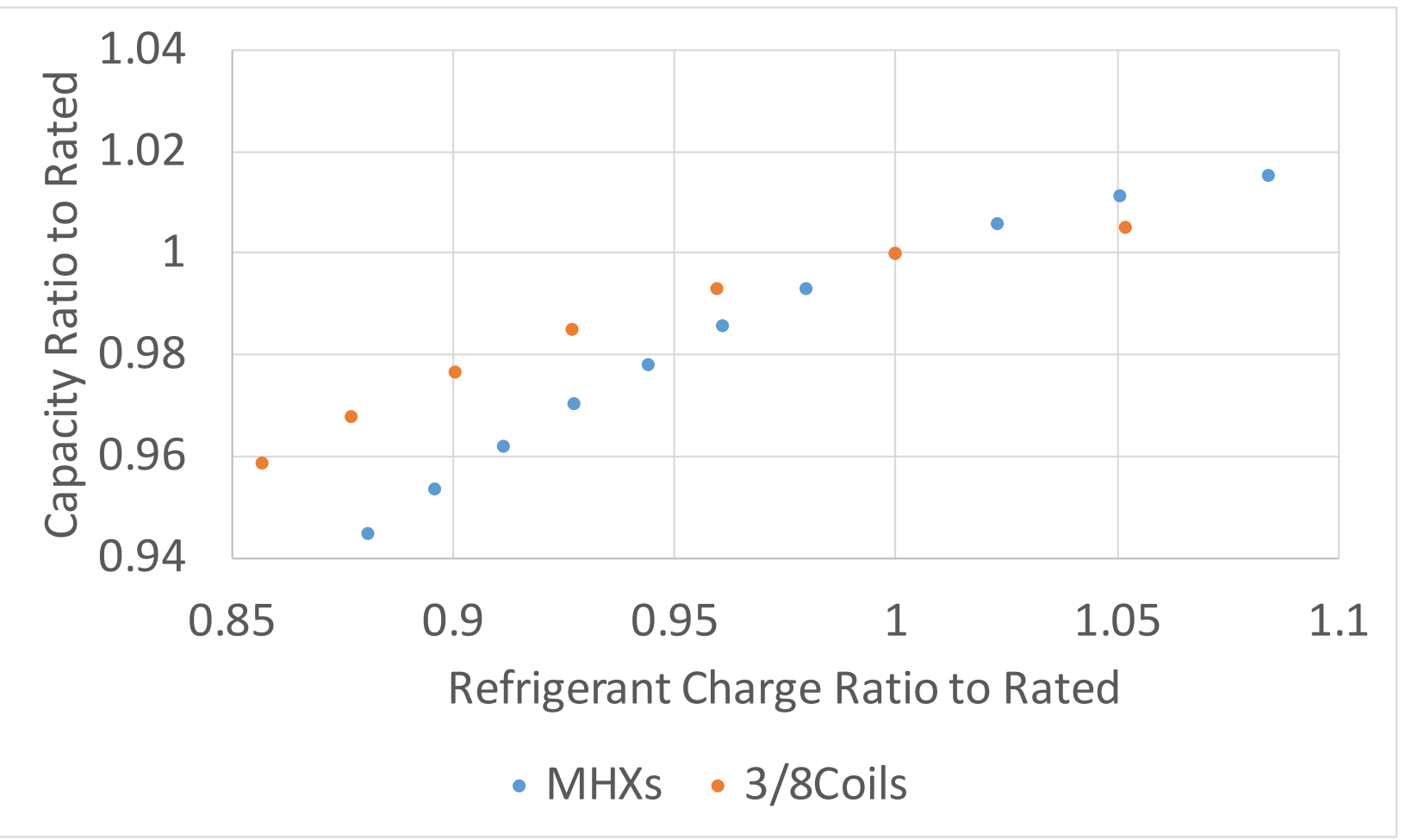

Figure 4: Cooling capacities change with the system charge 


\section{Summary}

Regarding charge reduction opportunities, in general, it is recommended:

1. Downsizing the outdoor condenser will reduce the required system charge, i.e. using smaller tube diameters or fewer tubes; reducing the evaporator inner volume is less important; to offset the reduced condenser tube side surface area, one can increase the air side surface area (fin density) or condenser air flow rate via using a more efficient fan.

2. microchannel heat exchangers are most effective in reducing the required charge, by up to $60 \%$ in the condenser and evaporator. To develop low charge systems, one should at least use a microchannel heat exchanger as the outdoor condenser.

3. TXV systems are less sensitive to charge reduction. For the drop-in application, one can decrease the charge to minimize the liquid section in the condenser, at the expense of minor performance degradation; for example, when reducing the system charge by $15 \%$ (decrease the subcooling degree to $2 \mathrm{R}$ ), the simulation results prove that the decrease is less than $3 \%$ in the EER and less than $6 \%$ in the capacity. 